Revista de Sociología

№ 19 - 2005

Facultad de Ciencias Sociales - Universidad de Chile

(p. 51-70)

\title{
BRASIL: OS DESAFIOS DAS REFORMAS E AVALIAÇÃO DA EDUCAÇÃO SUPERIOR*
}

\section{Hélgio Trindade ${ }^{1}$}

0 tema da reforma universitária atravessa a história da universidade latinoamericana há quase um século. Desde a reforma de Córdoba na Argentina, no início do século XX, se tornou o modelo de referência das universidades latinoamericanas. No Brasil, a partir da década de 1960, a União Nacional de Estudantes (UNE) assumiu essa bandeira de luta através da greve pelo co-governo da universidade. Mesmo a lei universitária de 1968, em plena ditadura militar, reconheceu que 0 movimento estudantil tivera um papel fundamental na tomada de consciência nacional da importância da questão universitária e admitiu, ainda que de forma restrita, o princípio da representação estudantil nos órgãos colegiados da universidade. 0 conceito de reforma universitária permaneceu, até hoje, na memória política como uma referência simbólica de uma concepção de universidade com missão acadêmica, compromisso social e gestão democrática.

Até 0 último quartel do século XX, a idéia de universidade pública na América Latina esteve fortemente associada ao Estado desenvolvimentista. No Brasil, este modelo de universidade decorreu (salvo nos casos da USP e da UDF) de um modelo estatal implantado a partir da Revolução de 1930 associado a "um modelo amplo de organização da sociedade a partir do Estado através da criação de um conjunto de agências e empresas estatais".

“Esse modelo é mantido em 1946, em 1967 e parcialmente em 1988. Nesse sentido, parece claro uma primeira característica da Universidade brasileira, é a sua constituição como um projeto estatal que repete as mesmas características do Estado-desenvolvimentista. A pesar da autonomia reivindicada e concedida, ainda nos anos 30, as principais modificações da

\footnotetext{
*Professor-titular de Ciência Política e ex-reitor da Universidade Federal do Rio Grande do Sul. Atualmente Presidente da Comissão Nacional de Avaliação da Educação Superior (CONAES).

${ }^{1}$ Foi o organizador do livro: U niversidade em Rúnas na República dos Professores. 3o edição. Petrópolis, RJ: Vozes, 2003; sendo autor, dentre outras obras, de "A urgência da autonomia universitária" in Mohry, Lauro (org) U niversidade em questão. Brasília: Editora UnB, 2003; "Por que e como reformar a universidade: mitos e realidades". In A universidade na encruzilhada. Seminário U niversidade: por quê e como reformar?. Brasília: UNESCO Brasil, MEC, 2003.
} 
universidade brasileira obedecerão a uma lógica primariamente estatal. Será o Estado que irálegislar sobre elementos fundamentais, tais como, a estrutura funcional (sistema de departamentos), a democracia interna (órgãos decisórios) e a forma de produção e reprodução do conhecimento (unidade entre ensino e pesquisa)". (AVRITZER,UFMG mimeo, 2002, p. 15).

\section{Reformas e contra-reformas na América Latina no final século XX}

Balanços feitos sobre reformas educativas na América Latina mostraram que a geração de reformas, ao final do século XX, caracterizou-se fundamentalmente por mudanças: "nos modelos de financiamento, exigência de eficiência através da implantação de sistemas avaliativos e pressões por relações mais estreitas com 0 setor produtivo. Em grande parte dos países da América Latina as transformações derivadas dessa geração de reformas tiveram lugar na década dos 90, exceto o Chile cuja reforma começou nos 80". (Guadilla, 2003: 19).

A tualmente, no Brasil, estamos diante de novas perspectivas que poderão se abrir num futuro próximo e desafiados a assumir a nossa parte, superando a síndrome tradicional da resistência. 0 desafio agora é participar da reestruturação da educação brasileira aqui e agora. Essa perspectiva é compartilhada por Marcela Mollis, coordenadora do GT de Educação Superior da CLACSO : "...apesar das preocupações dominante com curto prazo temos um futuro a construir e as universidades que sobreviveram planificaram currículos integrados, interdisciplinares, e se preocuparam em voltar a educar a sensibilidade para a pluralidade. $\mathrm{O}$ hommo economicus e o comprador de diplomas teria passado à historia da razão moderna. É nossa utopia pós neoliberal". (Mollis, 2003: 14).

Não basta, porém, reconhecer este lugar comum de que estamos submetidos a um processo de mundialização diante do qual temos que abandonar qualquer projeto de Nação soberana e que a sociedade do conhecimento ou da informação seria a única referência válida para o futuro da educação superior. Embora a mídia, os especialistas e os organismos internacionais circulem esses conceitos de forma abstrata e quase mágica, é fundamental não sucumbir à lógica circular da reprodução dos argumentos.

D ois estudos recentes de Carnoy - "M undialização e reformas da $\mathrm{E}$ ducação: 0 que os planejadores devem saber" (1986); e "E stá a educação latino-americana preparando a força de trabalho para as economias do século X X I?" (2004) - trazem reflexões no campo da reforma universitária para a América Latina. D entre os dois textos, o que aborda a América Latina é mais rico empiricamente, embora do ponto de vista conceitual o primeiro seja, a meu juízo, mais pertinente. 
Merece destaque sua análise sobre "as conseqüências diretas ou indiretas da mundialização sobre os sistemas educativos", como decorrência da "evolução do mercado do emprego com uma nova demanda de mão de obra com alto valor agregado por sua maior densidade tecnológica" e a "necessidade de créditos suplementares para educação num contexto de uma conjuntura hostil a expansão do setor público" E acrescenta que "se o saber é essencial à mundialização, esta deve ter uma profunda incidência sobre a transmissão do saber" e os dois ingredientes essenciais são a informação e a inovação. $O$ autor faz uma distinção importante entre mundialização e o uso ideológico que dela se faz. Traz o exemplo da descentralização na educação, que pode ser uma manifestação da mundialização que modifica o poder político, mas pode ser fruto de uma ideologia que considera a burocracia estatal como um obstáculo inerente ao desenvolvimento do setor privado. 0 estudo destaca "que os créditos para o ensino superior aumentam no mundo em função das novas orientações da produção econômica voltada para produtos de forte densidade de saber", mas observa que os capitais financeiros internacionais "têm interesses econômicos de curto prazo, tendem a favorecer 0 setor privado", pressionando os governos a frear o crescimento das despesas públicas. E conclui: "Este projeto mais amplo de restrição à despesa pública no campo da educação corre o risco de impedir os Estados de escolher os meios mais eficazes de desenvolver e melhorar o ensino no contexto da nova economia mundial." (Carnoy, 1999:17).

O autor parte sua análise do impacto da mundialização sobre as estratégias das reformas da educação: as "fundadas na competitividade" (OECD, UNE SCO); ou dominadas pelos "imperativos financeiros" (FMI) para reduzir as "despesas públicas em educação e privatização do ensino secundário e superior" (idem: 49). D estaca, finalmente, as reformas "baseadas na eqüidade", cujo objetivo central é "aumentar a igualdade de chances econômicas, já que o rendimento escolar é um fator primordial para determinar os salários e o nível social da maioria do país. (...) Na nova economia global, as condições dependerão cada vez mais da maneira como o Estado organizará o sistema educativo" e "o valor do conhecimento sendo o bem mais reconhecido na economia mundial, as nações não tem outra escolha do que aumentar seus investimentos em educação" (ibidem: 91).

No campo do ensino superior latino-americano há, porém, algumas contradições entre as mais altas coberturas da matrícula e a qualidade massificada do ensino e as limitações da pesquisa, embora com baixo nível de privatização (inferiores a 25\% ), onde os casos do México, da Argentina e Uruguai poderiam ser bons exemplos. Os países com forte presença de matrícula no ensino privado, (Brasil, Colômbia e Chile) tendem a valorizar a experiência chilena, apesar da alguns 
aspectos críticos: não parece aceitável que a redução do financiamento estatal das universidades públicas a 35\% seja uma tendência compatível com o papel do Estado no estímulo ao ensino e a pesquisa. 0 caso brasileiro é, porém, o mais complexo: tem um sistema público de educação superior de melhor qualidade do que a maioria dos países latino-americanos (só o México poderia ser comparável), que coexiste com um sistema privado que dispõe de mais de $75 \%$ da matrícula. Num ranking internacional dos anos 90, o Brasil era o terceiro pais em privatização do ensino superior na América Latina, excetuando-se alguns pequenos países da América Central e o sétimo em termos mundiais, antecedido de alguns países asiáticos. (Guadilla, 1996)

\section{Do privatismo liberal-positivista ao nacional-autoritarismo da Revolução de 1930}

Na história da República no Brasil, as duas leis gerais sobre educação superior que tiveram uma longa vigência foram promulgadas: a primeira, em 1931, por Francisco Campos durante o Governo Provisório de Vargas pós-Revolução de 19302; a segunda, em 1968, pelo Ministro da Educação, Tarso Dutra, durante a ditadura militar instaurada em 1964 que ainda está em vigor. A legislação em que provavelmente desembocará a nova reforma será a primeira a ser construída num período democrático, o que implica em amplo debate com os segmentos representativos da comunidade universitária e da sociedade.

No início da República ocorreu uma das singularidades do nosso ensino superior em termos latino-americanos. Além da tardiaimplantação das universidades, com uma distância de mais quatro séculos entre a colônia portuguesa e a hispânica (1538 em Santo D omingos e em 1934 em São Paulo), a República brasileira rompeu com o ensino superior "oficial" das faculdades e escolas profissionais do período da monarquia imperial. Foi o ministro positivista Benjamin Constant, responsável pela instrução pública que, se opondo ao privilégio dos diplomas, permitiu 0 desenvolvimento de instituições "livres", "não dependentes do Estado, empreendidas por particulares". Mas foi a Lei O rgânica de 1915 que "estabeleceu que as escolas superiores criadas pelos estados e por particulares deixavam de sofrer qualquer fiscalização por parte do governo federal", com currículos organizados sem qualquer paradigma oficial. Na realidade, "os estabelecimentos governamentais

${ }^{2} O$ primeiro Decreto de Lei Orgânica do Ensino Superior e do Fundamental na República foi do Marechal Hermes da Fonseca e redigida pelo deputado gaúcho Rivadávia da Cunha Correa (1911-1915). 
passariam a ser corporações autônomas", gozando de "completa autonomia didática, administrativa e financeira" ${ }^{3}$. (Cunha, 1980, 162)

A reforma da era Vargas não pode ser compreendida sem 0 debate educacional que a precedeu com a fundação da Associação Brasileira de Educação (ABE), em 1924. Em vários Estados houve reformas do ensino conduzidas por profissionais da educação, observando-se uma "crescente influência cultural norteamericana no Brasil" da qual a ABE foi "poderosa caixa de ressonância" (idem, 1980:196-198)4. O utro fato relevante foi o "Inquérito" sobre a situação da instrução pública em São Paulo (1926), conduzido pelo jornalista Fernando de Azevedo, a pedido de Júlio Mesquita Filho, diretor do jornal Estado de São Paulo ${ }^{5}$. As propostas decorrentes da pesquisa reforçavam "a tendência liberal-elitista do seu autor que propunha a menor intervenção política no processo e 0 incentivo do governo à iniciativa privada" ${ }^{6}$ (Ibidem, 199-200).

Em 1927, realizou-se no Rio de Janeiro um Congresso do Ensino Superior comemorativo ao centenário dos cursos jurídicos no Brasil, no qual foi proposto que "todo 0 ensino no Brasil deve ser organizado de forma universitária e, para isso, deve ser elaborada uma lei regulamentando a criação de universidades, inclusive de universidades livres; a formação das universidades deve partir de duas faculdades destinadas ao ensino profissional (..) às quais se acrescentaria uma faculdade de letras e outra de ciências e altos estudos, sendo o ensino gratuito nestas últimas." . Já na II Conferência Nacional de Educação da ABE, em Belo Horizonte (1928), foi a proposta do Reitor Tobias Moscoso da URJ que foi adotada: "não deve haver um tipo único de universidade para todo o país; cada universidade deve se organizar segundo suas condições peculiares e as da região". (idem:201-202).

Com a Revolução de 1930, o contexto político e econômico colocou em pauta duas políticas educacionais em confronto: a liberal-elitista e a nacionalautoritária: "a política liberal não resultou de um programa definido nem teve desdobramento homogêneo", passando de um "liberalismo elitista", a partir de

${ }^{3} \mathrm{O}$ D ecreto 11.530, de 1915, do jurista gaúcho Carlos Maximiliano, estabeleceu o privilégio dos diplomas do Colégio Pedro II no acesso ao ensino superior; da instituição dos exames de admissão para o ensino superior e criação da figura do "professor catedrático" vitalício. Ibidem, 162-163.

${ }^{4}$ Essa influência americana já se manifestara com a ciração de Carlos Chagas da Escola de Enfermagem, no Rio de Janeiro (1922), com apoio da Ford Foundation e a contratação de 11 professores norte-americanos.

${ }^{5}$ Mais tarde, com a Revolução de 1930 e a derrota da Revolução Constitucionalista de 1932, Júlio Mesquita Filho será um dos promotores da fundação da Escola de Sociologia e Política (1933) e da Universidade de São Paulo (1934). (Cunha, 1980:235-237).

${ }^{6}$ Segundo Cunha o dilema formulado por Francisco Venâncio Filho e assumido por Azevedo: 'O u nós educamos o povo para que dele surjam as elites, ou formamos elites para compreenderem a necessidade de educar o povo". (idem 1980:199200) O inquérito foi publicado por Fernando Azevedo no jornal O Estado de São Paulo em 192 e, posteriormente, editado em livro em 1960. 
1932, para um "liberalismo igualitarista", identificado com as camadas médias e trabalhadoras. A política nacional-autoritária se enraizou na década de 1920, durante o governo Arthur Bernardes, a fim de "impedir contestações à ordem social". O s conflitos entre as duas correntes desenvolveram-se entre 1930 e 1935, sendo que "o autoritarismo prevalecia na esfera do poder central" e nos Estados de São Paulo e no Distrito Federal dominavam as idéias liberais. A partir de 1935, a primeira corrente se impôs diante da "repressão generalizada", que "retirou as idéias educacionais liberais" e fechou, em 1939, a Universidade do Distrito Federal, criada por Anísio Teixeira por pressão da Igreja e com o implantação do Estado Novo 0 poder central monopoliza a criação das universidades. (Ibidem, 228-258).

É importante relembrar que o D ecreto no 19.851, de 11 de abril de 19317, assinado por G etúlio Vargas e Francisco Campos, instituiu o "Estatuto das Universidades Brasileiras", indicando que o ensino superior "obedecerá, de preferência, ao sistema universitário", podendo ainda ser ministrado por "institutos isolados": o primeiro será regido pelo referido Estatuto e as segundas pelos "respectivos regimentos". 0 D ecreto foi estruturado em vários títulos definidores das regras da institucionalização e de padronização do sistema público de educação superior "oficial" (criado por lei federal ou estadual), "oficializado" (equiparado à estrutura oficial federal ou estadual) ou "livre" (independente, regulando-se por estrutura própria). No Título I, define-se como "Fins do Ensino Universitário": "elevar o nível da cultura geral, estimular a investigação científica em quaisquer domínios; habilitar ao exercício de atividades que requerem preparo técnico e científico superior; enfim concorrer pela educação do indivíduo e da coletividade (...) para a grandeza na Nação e para 0 aperfeiçoamento da Humanidade" (Art.1). Segundo o D ecreto, a organização das universidades "atenderá primordialmente ao critério dos reclamos e necessidades do país" e "será orientada pelos fatores nacionais de ordem psíquica, social e econômica..."(Art.2). .

O formato geral para as universidades públicas brasileiras previsto no decreto estabelecia, como pré-condição para a sua "constituição", congregar pelo menos três dos seguintes unidades (Direito, Medicina, Engenharia e Educação, Ciências e Letras, sem referência à Filosofia); dispor de "capacidade didática" (professores, laboratórios etc) e "recursos financeiros concedidos pelos governos, por instituições privadas e por particulares" (Art.5) . Poderiam ser mantidas pela União, Estados ou "sob a forma de fundações ou de associações, por particulares, constituindo universidades federais, estaduais e livres" (Art.6). O s estatutos deverão ser aprovados pelo Ministro da Educação e Saúde Publica e "só poderão ser modificados por

${ }^{7}$ Todos os artigos referidos nos próximos parágrafos foram extraídos do Decreto № 19.851, de 11-04-1931.Senado Federal, Subsecretaria de Informações, www.senado,gov.br 
proposta do Conselho Universitário ao Ministro ouvido o Conselho Nacional de Educação (CNE) (Art 7).

Neste contexto organizacional de forte controle estatal, "as universidades gozarão de personalidade jurídica e de autonomia administrativa, didática e disciplinar" nos limites do D ecreto (Art. 9), admitindo-se "ampliar pela incorporação de novos Institutos, com previa aprovação Conselho Universitário" (Art. 11). É relevante destacar que o ensino deveria ser pago, mesmo nas universidades oficiais. Exceto às instituições federais, "as universidades estaduais ou livres poderão ser equiparadas as federais para efeito de "concessão de títulos" mediante inspeção prévia pelo D epartamento Nacional de Ensino, ouvido o CNE" (art. 12) e estas "ficarão sujeitas à fiscalização do governo federal por intermédio do D epartamento Nacional de Educação (D NE)" e "poderá ser suspensa enquanto não forem sanadas graves irregularidades" ou fechada por D ecreto do Governo Federal, com prévio inquérito, ouvido o CNE (art.13).

Com relação às instâncias decisórias, as universidades deveriam ser administradas: por um Reitor e por um Conselho Universitário (incluindo a Secretaria G eral e a Contabilidade etc). 0 Reitor nas universidades federais e estaduais será de nomeação dos respectivos governos, devendo a escolha recair em nome constante da lista tríplice, organizada em votação uninominal pelos respectivos Conselhos Universitários (art. 17). Além das atribuições do Reitor e do Conselho Universitário (art.18 e 22), foi prevista também uma Assembléia Universitária “constituída pelo conjunto dos professores de todos os Institutos Universitários" (art 24). A administração dos Institutos Universitários se estruturava através do Diretor; do Conselho Técnico Administrativo e da Congregação. E a carreira docente se hierarquizava em "professores catedráticos, auxiliares de ensino, docentes livres e eventualmente de professores contratados" (art.48).

Finalmente, sobre a organização didática, a "extensão universitária será efetivada por meio de cursos e conferências de caráter educacional ou utilitário" e "destinam-se principalmente à difusão de conhecimento úteis à vida social e coletiva, à solução de problemas sociais e à propagação de idéias e princípios que salvaguardem os altos interesses nacionais" (art. 42 \& único). Também a "vida social universitária" foi concebida pelo decreto através de alguns órgãos estruturantes: as associações de classe, constituídas por docentes ("Sociedade de Professores Universitários") e discentes ("D iretório Central dos estudantes"), cujos estatutos deveriam ser aprovados pelo Conselho Universitário. Foram previstos congressos universitários de dois em dois anos; museu social para "congregar elementos de informação e pesquisa e de propaganda para o estudo dos problemas econômicos e sociais e culturais que mais interessam o país" (arts 101-110) 
Em 1930 havia somente duas universidades no país: a do Rio de Janeiro (1920) e a de Minas G erais (1927), mas, em 1946, esse número ampliou-se para seis instituições universitárias: a Universidade Técnica do Rio Grande do Sul (1932) posteriormente, Universidade de Porto Alegre (1934); a Universidade de São Paulo (1934); a Universidade do D istrito Federal (1935) e as "faculdades católicas" (1940), como embrião da PUC-RJ (1946) ${ }^{8}$.

\section{Da mobilização pela reforma universitária à modernização conservadora da ditadura militar}

As velhas bandeiras da Reforma Universitária de Córdoba (1918) chegaram tardiamente ao Brasil, através da UNE, no início dos anos $1960^{9}$. Após vários seminários e debates nacionais e regionais, desencadeou-se nacionalmente a "greve do terço" pelo co-governo das universidades. A mobilização em torno da reforma universitária, como parte das "reformas de base", politizou o movimento estudantil que foi radicalizando suas posições. A partir da "campanha da legalidade", a UNE se engajou, apoiando o então governador do Rio Grande do Sul Leonel Brizola, em defesa da posse de João Goulart na Presidência da República. O veículo da tomada de consciência em favor da reforma universitária foram a "UNE volante" e o Centro de Cultura Popular (CPC) que percorreram o país, partindo de Porto Alegre, com 0 apoio do governo do Rio G rande do Sul. 0 resultado desse processo, em um contexto ideologizado pela Revolução Cubana, foi a tomada de consciência de amplos setores sociais urbanos da importância da reforma universitária, cujas bandeiras principais eram: a democratização do acesso; a extinção da cátedra vitalícia; autonomia universitária, compromisso social e o co-governo nos órgãos colegiados.

Esse processo foi brutalmente interrompido pelo golpe militar de 1964, com a sede da UNE incendiada, professores cassados e estudantes presos, mas ficou ainda presente na memória histórica e ressurgiu das cinzas nas mobilizações estudantis, durante 0 ano de 1968, até 0 aprofundamento da ditadura, com a edição do AI-5. A problemática da educação sempre esteve presente nas preocupações dos militares e de seus aliados civis desde 1962, inclusive financiando estudantes que atuavam na política estudantil para enfrentar os "comunistas" no controle da UNE. Q uestionava-se a universidade engajada e crítica através de alternativas concretas para os diferentes níveis de educação.

\footnotetext{
${ }^{8} \mathrm{Em} 1940$ o CNE autorizou o funcionamento no Rio de Janeiro da Faculdade de Direito e mais sete cursos na Faculdade de Filosofia e sua transformação na primeira PUC do Brasil (D ec. 8.681 de 15-03-1946).

${ }^{9}$ Embora em 1928 tenha havido um manifesto de estudantes do Rio de Janeiro em favor da reforma de Córdoba, este episódio não teve, na época, nenhum efeito prático.
} 
Com a tomada do poder, o interesse do governo militar pela modernização das universidades já se encontra no Programa de Ação Econômica do Governo (1964-1966) e educação passa a ser considerada capital humano. Era a retomada do projeto que o Instituto de Pesquisas E conômico e Social (IPES) havia elaborado para país antes de 1964 para se contrapor às reformas de base..$^{10}$ Encerrada a primeira fase das medidas repressivas contra professores e estudantes, efetivadas pelo Ministro Flávio Suplicy de Lacerda, a nomeação para o MEC de Raymundo Muniz de Aragão durante o governo Castello Branco criou as condições para ser adotado um modelo institucional modernizador, inspirado nas universidades americanas, cujo referencial interno já implantado era a Universidade de Brasília ${ }^{11}$.

Em agosto de 1966, o novo Ministro solicitou parecer sobre a reformulação das universidades federais ao Conselho Federal de Educação (CFE), cuja resposta foi o parecer do conselheiro Valnir Chagas, acompanhada de um anteprojeto de lei. Este foi rapidamente transformado no D ecreto-lei 53 de 1966, onde já estavam presentes alguns dos traços estruturantes da lei universitária de 1968: vedava a duplicação de meios para fins idênticos; propunha a indissociabilidade do ensinopesquisa; separação do ensino profissional e da pesquisa aplicada em unidades distintas; 0 fim das Faculdades de Filosofia, Ciências e Letras, abrindo o caminho para as unidades especializadas e a criação das Faculdades (Centros) de Educação; e suspensão das garantias de vitaliciedade, inamovibilidade e estabilidade dos funcionários públicos para assegurar a remoção dos respectivos titulares. Finalmente, o Decreto-lei $n^{\circ} 252$ implantava os departamentos como a menor fração da estrutura universitária, cujo chefe deveria ser um professor catedrático. Estes chefes, reunidos, constituiriam o conselho departamental da unidade.

D iante do ressurgimento do movimento estudantil em 1968, os militares resolveram entrar diretamente no processo de reforma. Primeiro, com o Seminário de Educação e Segurança Nacional, reunindo a Escola de Comando e Estado Maior do Exército (ECME) e a Universidade do Estado da Guanabara em torno de alguns temas, tais como: intercâmbio entre ensino superior e secundário civil e militar e educação para a cidadania, donde surge a proposta do ensino de Moral e Cívica e o Projeto Rondon ${ }^{12}$. Segundo, a instalação da comissão do G eneral Meira Matos, em 1967, provocou uma quase intervenção no MEC para encontrar respostas

\footnotetext{
${ }^{10}$ Sobre o papel do IPES na fase da conspiração do golpe, articulando empresários e militares, ver D REIFUSS, R. 1964:a conquista do E stado. A ção política, poder e golpe de dasse. Petrópolis, RJ: Vozes, 1981.

${ }^{11}$ Sobre a criação da Universidade de Brasília ver: RIBEIRO, Darcy. A U niversidade de Braślia na Comissão de E ducação e Cultura da Câmara dos D eputados.Brasília, D epartamento de Imprensa Nacional, 1963; SALMERON, Roberto A. A U niversidade interrompida 1964-1965. Brasília: Ed. UnB, 1998. Mas essa influência americana já se fazia presente desde a criação do Instituto Tecnológico daA eronáutica (ITA) e da Faculdade de Medicina de Ribeirão Preto.

${ }^{12}$ Daí surgiria 0 embrião do Projeto Rondon, cujo Grupo Piloto foi constituído pela Universidade da Guanabara, em julho de 1967, e com o AI-5 a proposta de ensino de moral e cívica em todos os níveis.
} 
às reivindicações estudantis ${ }^{13}$. A comissão criticou "a implantação lenta e desordenada da reforma universitária" e salientou a improdutividade do "professor ocioso e o espaço ocioso", propondo a sua contratação pela legislação trabalhista e a busca de novas fontes de financiamento para atender a expansão da demanda pela supressão da gratuidade ou pela criação de um Banco Nacional da Educação ou um fundo rotativo de bolsas de estudo (Cunha, 1988: 100-104).

Se a modernização do ensino superior no Brasil sob a influência do modelo americano começou em meados de 1940, a ditadura militar determinou uma mudança qualitativa nesse processo. Na realidade, a relação mais estreita com os EUA começou ainda sob a presidência de Goulart, com a vinda dos primeiros consultores, em início de 1963 (H igher E ducation Team) O relatório dos consultores propunha que a "assistência" do governo se direcionasse para os planejadores de políticas na área (MEC, CFE e conselhos estaduais de educação) e recomendava a criação de um conselho de reitores a ser financiado pela USAID - esta foi a origem do CRUB. As mobilizações do movimento estudantil, a recusa do CFE em assinar o convênio e as demissões de membros nomeados pelo governo para integrar ao EPES, levaram a USAID a cancelar unilateralmente 0 convênio ${ }^{14}$.

Nesse processo, a Lei Universitária 5.540, de 1968 resultou de um "Anteprojeto de Lei sobre organização e funcionamento do ensino superior", elaborado por um "Grupo de Trabalho" de onze membros ${ }^{15}$, designado pelo Presidente Costa e Silva e presididos pelo Ministro da Educação Tarso Dutra. 0 GT recebeu a incumbência de "estudar a Reforma da Universidade brasileira visando à sua eficiência, modernização, flexibilidade administrativa e formação de recursos humanos de alto nível para o desenvolvimento do país" (art.19), com prazo de trinta dias para encaminhar sua proposta ${ }^{16}$. Do relatório pode-se extrair as linhas gerais e o sentido prático do trabalho: "não se trata, pois, de formular o diagnóstico da presente crise universitária, nem mesmo de traçar os delineamentos de uma reforma, sim propor um repertório de soluọoes realistas e de medidas operacionais que

\footnotetext{
${ }^{13} \mathrm{~A}$ Comissão, presidida pelo General Meira Mattos, teve como membros: Prof. Helio de Souza Gomes, Diretor da Faculdade de D ireito da UFRJ; Prof. Jorge Boaventura de Souza e Silva, do MEC; pelo Promotor Afonso Carlos Agapito da Veiga e o Coronel-Aviador Waldir Vasconcelos, secretário do Conselho de Segurança Nacional (Cunha, 1988:5).

${ }^{14}$ Foi o ministro Suplicy de Lacerda que assinou o convênio com a USAID, em junho de 1965, do qual se originou a Equipe de Planejamento da Educação Superior (EPES), com recursos previstos da ordem de 500 mil dólares. Foram concedidas 3.800 bolsas para brasileiros nos Estados Unidos entre 1965 e 1970. Maiores detalhes sobre a relação entre 0 governo militar e a USAID (Cunha, 1988:168-239).

${ }^{15}$ O s membros do GT foram: Tarso D utra, presidente, Antonio Moreira Couceiro, Fernando Bastos de Ávila, Fernando Ribeiro do Val, Haroldo Leon Perez, João Carlos Moreira Bessa, João Lyra Filho, João Paulo dos Reis Velloso, Newton Sucupira, Paulo Bouças, Roberto Spencer Maciel de Barros, Valnir Chagas. Os estudantes declinaram da nomeação. Fonte: R elatório elaborado pelo G rupo de Trabalho da Reforma U niversitária (G TRU),Brasília, setembro, 1968.

${ }^{16}$ Relatório GTRU: pp.5-20).
} 
permitam racionalizar a organização das atividades universitárias, conferindo-lhes maior eficiência e produtividade." Adiante, o relatório reafirmava que "o objetivo do grupo não, é portanto, fazer a reforma universitária, mas induzi-la" sob duplo aspecto: "removendo os óbices, eliminando pontos de estrangulamento que entravam a dinâmica universitária" e "proporcionando meios" que "possibilitem sua autorealização na linha de uma conciliação difícil, mas necessária, entre o ensino de massa" e "a missão permanente da Universidade, de constituir-se o centro criador de ciência e a expressão mais alta da cultura de um povo"(Idem:19-20)

O GT considerava que a "universidade não se constitui um universo encerrado em si mesmo, capaz de reformar-se por suas próprias forças (...) A Universidade não pode ser a única instância decisória de sua inserção na sociedade". Sugere que "a verdadeira reforma universitária se processa no entrechoque de uma tríplice dialética: relação entre o Estado e a Universidade, numa espécie de debate vertical; relação entre a Universidade e as múltiplas forças da comunidade" e "no interior dela mesma, como revisão interna na dialética do mestre e do aluno"(Ibidem:20).

O relatório enfrentou, também, em sua parte geral, as relações entre E stado e autonomia universitária: "a universidade é o ponto de cruzamento de movimentos sociais e de cultura" e "se acha integrada no sistemas de forças do qual o Estado deve ser o fator de equilíbrio" (...) mas "se justifica, e mesmo se impõe, a ação estimuladora e disciplinadora do Estado". Por outro lado, a Universidade, nos termos do Relatório "não pode ser o refúgio dos puros intelectuais desenraizados ou de um saber sem compromissos, divorciada da realidade prática", mas há que "levar em conta as legítimas aspirações culturais de uma juventude que procura situar-se no mundo moderno e compreender o sentido de seu momento histórico.". Daí a importância, atribuída pelo GT, à universidade: "como centro onde a cultura de um povo tende a atingir a plenitude de sua autoconsciência" (Ibidem:24-25).

A proposta transformada em lei deixou em aberto o regime jurídico e administrativo "admitindo que as universidades se organizassem sob a forma de autarquia, fundação ou associação" e, mesmo organizadas "sob a forma jurídica de direito privado, não se desvincularão do poder público, na hipótese de serem por eles mantidas" (Ibidem: 27).

Entre o Anteprojeto do GT e a Lei 5.040, houve, porém, uma série de vetos que modificou a sua forma original. A própria definição de "ensino superior", por exemplo, foi vetada parcialmente. O Anteprojeto mencionava que: "o ensino superior, indissociável da pesquisa, será ministrado em universidades e excepcionalmente em estabelecimentos isolados organizados como instituições de 
direito público e provado" (Ibidem:1971) e Lei dá uma nova redação". 0 ensino superior tem por objetivo a pesquisa, o desenvolvimento das ciências, letras e arte e a formação de profissionais de nível universitário" ${ }^{17}$

Q uanto à autonomia, no entanto, não houve nenhum veto ou mudança no texto: "as universidades gozarão de autonomia didático-científica, disciplinar, financeira e administrativa, que será exercida na forma da lei e de seus estatutos" (art.3) Com relação à organização das instituições, há uma clara definição de sua natureza legal: as universidades e os estabelecimentos isolados constituir-seão, quando oficiais, em autarquias de regime especial ou em fundações de direito público e, quando particulares, como fundações ou associações. Finalmente, alguns princípios foram definidos sobre a organização das universidades: unidade de patrimônio de administração; estrutura orgânica com base em departamentos; unidade de funções de ensino e pesquisa; vedada a duplicação de meios para fins idênticos; racionalidade de organização, com plena utilização de recursos humanos; universalidade de campo; flexibilidade de matérias e critérios.

A Lei de 1968 não esgotou a reforma, mas foi acompanhada de uma série de ante-projetos de leis complementares: alteração do Estatuto de Magistério Superior Federal; criação do Fundo Nacional de Desenvolvimento da Educação; incentivos fiscais para o desenvolvimento da educação; adicional do Imposto de Renda para 0 financiamento de pesquisas relevantes para a tecnologia nacional; modifica a destinação do Fundo Especial da Loteria Federal. Além dos decretos que instituem os Centros Regionais de Pós-G raduação; programa de incentivo à implantação do regime de dedicação exclusiva; critérios de expansão do ensino superior; exclusão de contenção as dotações orçamentárias do $\mathrm{MEC}^{18}$.

Se a "Reforma de 1968" modernizou e profissionalizou as universidades públicas, sua burocratização foi o outro lado da moeda: esta tornou-se mais uma organização complexa do que uma instituição social dentro da tradição latinoamericana. Sua estratégia foi comandada por um vigoroso sistema de pós-graduação que se introjetou nas estruturas profissionalizantes das universidades tradicionais. Foi indiscutivelmente um avanço em termos latino-americanos (especialmente diante do desmantelamento produzido pelos outros regimes militares do Cone Sul), mas essa política teve um efeito perverso: provocou uma crescente privatização da educação superior. Hoje, o sistema de educação superior está fragmentado, banalizou-se o conceito de universidade e houve um crescimento descontrolado das instituições privadas. Esse contexto perverso de alta privatização sem

${ }^{17}$ Vide Lei 5040 de 28 de novembro de 1968.

${ }^{18 V}$ Vide Relatório GTRU pp.69-117. 
planejamento e um sistema público com universidades de pequeno porte em termos latino-americanos, é uma das questões centrais que deverá enfrentar a nova reforma universitária.

\section{Brasil 2005: a reforma da educação superior como prioridade}

No início do segundo ano do governo Lula, com a mudança do titular do Ministério da Educação, a "reforma universitária" foi trazida para a agenda das prioridades do governo depois de várias décadas. Este é um fato por si mesmo significativo, uma vez que, durante o primeiro ano do governo, a questão foi tratada em seminários nacionais e internacionais ${ }^{19}$ sem que houvesse um compromisso com um cronograma de ações voltadas para a sua implementação. O principal avanço foi a iniciativa da Secretaria Educação Superior do Ministério da Educação/ $\mathrm{SE} \mathrm{Su}$, em meados de 2003 , de criar uma Comissão $\mathrm{E}$ special de A valiação $0^{20}$ que elaborou a proposta de um novo Sistema Nacional de Avaliação Institucional (SINAES), aprovado pelo Congresso através da Lei no 10.861 de 14 de abril de 2004 e, atualmente, em fase de implantação sob a responsabilidade de uma recém-criada Comissão Nacional de Avaliação da Educação Superior.

Há que se reconhecer, desde logo, o fato de que o Ministro Tarso Genro, ao instituir 0 Grupo Executivo da Reforma Universitária, sob sua presidência, desencadeou um processo com cronograma definido, prevendo amplos debates com entidades representativas dos reitores, segmentos da comunidade acadêmica e setores mais amplos da sociedade através de "audiências públicas regionais". A pesar da complexidade da metodologia adotada, o processo de discussão está se desenvolvendo num ritmo regular encaminhando-se para discussões regionais nas quais serão submetidas ao debate as propostas acumuladas.

A metodologia utilizado pelo atual Grupo Executivo de Reforma Universitária e seu conteúdo acumulado não assegura, a priori, o sucesso da reforma da educação superior. No entanto, diante dos diagnósticos e das propostas construídas no debate público e crítico, existe a perspectiva de que uma proposta

\footnotetext{
${ }^{19}$ O s seminários organizados pelo MEC foram: 1) Seminário Internacional U niversidade X X I - N ovos caminhos para a educação superior - 0 futuro em debate. 2003, Brasília. 2) Seminário U niversidade: por quê e como reformar? 25, 26 e 27 de novembro de 2003, Brasília.

${ }^{20} \mathrm{~A}$ Comissão Especial de Avaliação da Educação Superior (CEA) foi designada pelas Portarias MEC/ SE Su no 11 de 18 de abril de 2003 e no 19 de 27 de maio de 2003. Foi presidida pelo Prof. José Dias Sobrinho e integrada pelos seguintes membros: professores D ilvo Ristoff (UFSC), Edson Nunes (UCAM), Hélgio Trindade (UFRG S), Isaac Roitman (CAPES), Isaura Belloni (UnB), José Ederaldo Q ueiroz Telles (UFPR), José Geraldo de Souza Junior (SE Su), José Marcelino de Rezende Pinto (INEP), Julio César G odoy Bertolin (UPF), Maria A mélia Zainko (UFPR), Maria Beatriz Luce (UFRG S), Maria Isabel da Cunha (Unisinos), Maria JoséJackson Costa (UFPA), Mario Portugal Pederneiras (SESu), Nelson Cardoso Amaral (UFG), Raimundo Luís Araújo (INEP), Ricardo Martins (UnB), Silke Weber (UFPE) e Stela Maria Meneghel (FURB).
} 
democraticamente debatida responda aos compromissos do governo atual no campo da educação superior. A articulação entre as políticas do MEC no campo da educação superior e 0 debate democrático das propostas provavelmente se traduzirão num projeto que ofereça alternativas à situação crítica em que se encontra a educação superior brasileira, especialmente a pública, que defina as bases para a sua implementação. Diante de um quadro de hegemonia incontrastável dos segmentos privados de educação superior e de uma universidade pública bloqueada na sua expansão, há uma expectativa legítima de que o novo projeto de reforma corresponda a uma proposta republicana de reforma universitária a ser submetida ao Congresso Nacional.

A priorização do tema da reforma universitária é, de um lado, um ato de ousadia política diante da complexidade de sua elaboração participativa num contexto democrático, já que as leis universitárias anteriores foram elaboradas em situações autoritárias; e de outro, um desafio de alto risco político diante das tendências restritivas da economia brasileira para ampliar os níveis de financiamento público, as resistências tradicionais às mudanças das instituições públicas e a capacidade de pressão sobre o Congresso do setor privado.

No caso brasileiro, os desafios de uma reforma universitária a serem enfrentados são enormes e complexos. Afinal, a nova reforma deve ser capaz de responder questões emblemáticas, como: 1) qual o papel do Estado, no contexto da economia mundializada, para enfrentar a reforma de um sistema de público/ privado tão desequilibrado? 2) Q ual o nível de massificação aceitável para o sistema público de educação superior para que ele possa cumprir suas funções inovadoras na pesquisa fundamental e aplicada para as novas economias? 3) Q ual a função estratégica da universidade na construção de um projeto de Nação soberana e inserida na competição internacional na geração de conhecimentos científicos e tecnológicos?

Se houver uma revalorização do papel do sistema de educação superior no cumprimento de sua missão própria acadêmica e social, contribuindo com a formação de profissionais competentes, cientistas, humanistas e artistas - todos cidadãos- para o desenvolvimento econômico, social e cultural, a reforma terá também impacto sobre 0 aprofundamento da democracia. Nesse sentido, a velha bandeira da reforma universitária da democratização pela ampliação do acesso ao ensino superior precisa continuar viva, expandindo o sistema de todas as formas sob o impulso e supervisão do poder público.

Cunha avalia as varias alternativas de legislação para reformar a educação superior. Considera que "o ideal seria a elaboração de nova LD B", mas reconhece que, como "não é viável, no horizonte político previsível, nas atuais circunstâncias, 
será a elaboração de leis orgânicas que possam preencher lacunas e corrigir equívocos daquela lei." Daí decorre sua proposição de elaboração de uma Lei O rgânica do Ensino Superior que definisse "todo o ensino institucionalizado, como um serviço público passível de ser oferecido diretamente pelo Estado ou por instituições privadas" com "uma seção relativa às universidades e um capitulo dedicado ao sistema federal de ensino superior, inclusive as universidades federais." Esta nova lei trataria, com relação às universidades, "dos marcos da autonomia e definiria matérias importantes como a avaliação, abrangendo todas as instituições" e "importantes questões comuns a todas elas: financiamento, carreira, organização interna, escolha dos dirigentes e outras". Conclui que "o apoio do MEC a um projeto de Lei O rgânica do Ensino Superior, cuja elaboração o próprio MEC poderia patrocinar, seria a expressão nítida de uma atuação contrária a do governo passado, que primou pela indução à legislação fragmentada”. (Cunha, 2003:148-149)

É indispensável, porém, romper-se a lógica do governo anterior que aprofundou a privatização pela expansão descontrolada desse setor, e estabelecer critérios de um crescimento estrategicamente definido em função das necessidades nacionais e regionais, sem considerar-se que o único critério seja comandado pela demanda do mercado, respeitados os princípios constitucionais. D aí a importância da expansão de vagas, sobretudo, no setor público, com políticas de inclusão social, cursos noturnos, cotas para estudantes oriundos das escolas públicas do ensino médio e para os afro-descendentes que fazem parte do processo de democratização da educação superior. Essas políticas devem induzir as instituições dentro de certos parâmetros de referência, mas respeitando em nome da autonomia didático-científica as diferentes formas de sua aplicação regional.

Para além das questões específicas da universidade brasileira e da relação dos setores público/ privado sob a hegemonia sem freios do segundo, há uma crise mais ampla da própria instituição universitária. Como salienta Boaventura dos Santos, a centralidade da universidade enquanto lugar privilegiado da produção da alta cultura e do conhecimento científico avançado é um fenômeno do século XIX, representada pelo modelo da universidade prussiana, instituída por Humboldt. Esta concepção de universidade entrou em crise na Europa do após II G uerra Mundial, sobretudo, a partir dos anos sessenta, desembocando nas rebeliões universitárias de 1968. Esta "crise de hegemonia", diagnosticada pelo sociólogo português, decorre das contradições entre a "alta cultura" e a "cultura popular" e se rompe com relação seqüencial entre "educação" e "trabalho" (Santos, 1994:168).

Neste início de século XXI, certas organizações internacionais, ao forjarem os conceitos de "sociedade do conhecimento mundializada" e da educação como 
"bem público global" ${ }^{21}$, sinalizam o rompimento com qualquer projeto de inserção nacional soberana no processo. $\mathrm{O}$ bem público perde sua referência republicana e nacional para diluir-se na confluência entre a governança e as estratégias de expansão dos provedores educacionais transnacionais ${ }^{22}$ (Rodrigues, 2003).

O utro problema importante decorre do significado que o conceito de "reforma" adquiriu no contexto das políticas de ajuste econômico na América Latina e das experiências de reformas educativas em diferentes contextos internacionais nas últimas décadas. Analisando o que se passou na "república dos professores" ao longo dos oito anos do Governo Cardoso, as "reformas" constituíram-se, na verdade, em "contra-reformas" a partir das propostas do Ministério da Reforma do Estado (MARE). A expectativa é de que a reforma proposta pelo governo Lula não se confunda com as reformas neo-liberais e retome a tradição que o termo "reforma universitária" teve, desde Córdoba, na América Latina e mude a ortodoxia da política econômica dominante até agora.

É obvio que em política, nada sendo concedido por mero paternalismo estatal ou pela visão iluminada de déspotas esclarecidos, a reforma precisa ser apropriada pelos seus agentes sociais e institucionais para que cumpra seus objetivos num governo que tem o compromisso público, decorrente de sua eleição democrática de desenvolver um "projeto de nação soberana", ao qual a universidade deve se associar. Seria a perda de uma oportunidade histórica: de um lado, resistir à mudança diante esgotamento da lei universitária de 1968; de outro, construir um cenário alienante, seja pelaidealização da universidade da sociedade do conhecimento numa economia mundializada, seja pelo purismo ideológico-político de uma reforma que não responde a nenhum modelo historicamente possível.

O Ministro Tarso Genro, ao tratar do "desafio da reforma universitária" em Aula Magna proferida em março de 2004 na Universidade Federal da Juiz de Fora, reconheceu que "a reforma da universidade é um processo complexo que envolve um conjunto de interesses enraizados historicamente (...) num mundo com os principais paradigmas do pós-iluminismo em crise". Avança, a seguir, na análise da difícil conjuntura da reforma: "o processo reformador que estamos propondo ocorre num momento de enfraquecimento do Estado e de diluição negativa entre as fronteiras do Estado e a sociedade. A centralização como princípio estruturante submeteu-se não ao controle cidadão, mas à tutela do capital financeiro sobre a vida pública"(G enro,2004).

${ }^{21}$ Maiores detalhes vide World Bank - Construir sociedades de conocimiento: nuevos desafíos para la Educación Terciaria, Washington, 2002.

${ }^{22}$ Sobre os novos provedores ver Rodrigues: 2003. 
A abrangência dessa definição do campo de lutas intelectuais, de interesses contraditórios, de paradigmas em crise subjacente à reforma é reveladora da compreensão do Ministro da problemática, de sua complexidade e das tensões acumuladas que tem levado, muitas vezes, a uma atitude de mera resistência, paralisia ou até mesmo de alienação a modelos ideais buscados num passado reconstruído nostalgicamente ou projetados num futuro historicamente desencarnado, associado à mitológica "sociedade do conhecimento" ou de uma globalização ditada por interesses hegemônicos que definem a educação como "bem público global" (Banco Mundial, 2002:XIX).

Aplicando à educação superior a valorização sistêmica da educação em geral, o Ministro manifesta sua clara filiação à idéia da democratização da educação superior pela ampliação do acesso a setores excluídos, o que implicará, em conseqüência, em sua necessária expansão pública sob pena de congelá-la conservadoramente sem alterar significativamente 0 a relação público-privado que atingiu, no Brasil, um dos níveis mais perversos do planeta: "o acesso amplo das classes médias à universidade, que se operou lentamente a partir da Revolução de 30, foi um sensível impulso modernizante na sociedade brasileira, mas, hoje, está completamente esgotado. Isso implica em dizer que as formas de acesso permanecem conservadoras". (G enro, 2004)).

E o texto termina referindo-se a três temas complexos, urgentes e desafiadores: as relações entre Estado, sociedade e educação superior e a tensão permanente na conquista/ concessão da "autonomia universitária"; o financiamento das universidades públicas, a ser tratado como "investimento social de longo prazo" defendida pela UNESCO; e as complexas relações entre o poder público e um setor privado dominante, carente de regulação estatal. Considera que: "a questão da autonomia da universidade é outra das questões-chaves que devemos debater. A autonomia para a produção do saber e a sua socialização; a autonomia como liberdade de ciência; a autonomia como impedimento a que a universidade seja alvo de contingências do imediatismo da política; a autonomia para administrar-se, jamais como alienação da universidade no que se refere à interferência democrática da sociedade." Finalmente, lança um último desafio "articular de forma cooperativa e qualificadora as instituições públicas e privadas como elemento de sustentação do projeto de nação é uma tarefa enorme, que só vai ter sucesso se a universidade pública for ampliada, revalorizada e assumir funções de vanguarda nesse processo". (Idem, 2004).

Embora não se possa confundir o discurso com a realidade, é preciso admitir que o diagnóstico e algumas das questões centrais estão postas na mesa. A complexidade do quadro econômico e político, porém, nos alerta contra qualquer 
falso otimismo. A aposta política do MEC é ambiciosa e de alto risco, ainda que em política o risco seja inerente ao processo. A combinação entre a posição de não diálogo e de boicote a qualquer reforma por parte de segmentos minoritários e atuantes e o conservadorismo da comunidade universitária a qualquer ruptura com os hábitos rotinizados, não podem ser subestimados. Enfrentar os vários desafios que se articulam e assegurar que estes atinjam seus objetivos, sem renunciar aos avanços já conquistados, é politicamente muito complexo. No entanto, há uma metodologia participativa em curso, um progresso conceitual nos textos em debate que indicam as diretrizes do governo e a adesão convergente entre muitos atores representativos. Com avanços e recuos inerentes a um processo dessa complexidade, há que reconhecer que, na últimas décadas, o debate amplo sobre a educação superior e a vontade política do governo de implementar seus resultados nunca avançara tanto.

A educação superior está vivendo, em 2004, uma das conjunturas mais ricas das últimas décadas, especialmente para os que vêm participando do debate em torno da educação superior brasileira. Estamos superando a etapa da mera denúncia ou da resistência e sendo convocados e desafiados a construir alternativas transformadoras para a educação superior. 0 governo atual aceitou o desafio e colocou a reforma universitária como prioridade. Esse está sendo um debate público permanente e o tom crítico e pessimista do debate espalhava-se pelo Brasil eAmérica Latina com as metáforas que mostravam a situação de crise permanente da educação superior na região: universidade em ruínas, universidade na penumbra, universidade na encruzilhada o naufrágio da universidade.

O principal impasse durante os dois mandatos do governo anterior foi o de não ter enfrentado o trinômio avaliação-autonomia-financiamento. Na gestão do Ministro Paulo Renato, a autonomia transformou-se numa estratégia para reduzir o financiamento público. As várias tentativas de aprovar um projeto de autonomia fracassaram porque pretendiam descomprometer o Estado progressivamente do financiamento.

Autonomia sem avaliação significaria, igualmente, lançar a instituição social universidade no isolacionismo contraditório com sua identidade histórica. A universidade e a sociedade têm uma relação simbiótica, sem a qual a universidade reduz-se a uma organização complexa, apartada de seu entorno societal.

A universidade, enquanto instituição social, somente realiza plenamente a sua missão acadêmica e social se mantiver um equilíbrio dinâmico entre qualidade acadêmica, relevância social e equidade. A Carta Magna de Bolonha contém uma definição lapidar de universidade, colocando a autonomia como inerente à própria idéia de universidade: "A universidade, diversamente organizada dentro sociedade 
por condições geográficas e históricas, é a instituição autônoma que, de modo crítico, produz e transmite cultura através da pesquisa e do ensino" (Matteucci, 1991: 283).

Portanto, a autonomia é uma condição necessária ao próprio conceito multissecular de universidade, mas não suficiente: as universidades de qualquer natureza, públicas ou privadas, não podem feudalizar-se na autonomia como um fim em si. D aí a importância de um sistema de avaliação institucional que permite, periodicamente, verificar se ela está cumprindo, com qualidade, sua missão acadêmica e social; em outros termos, a missão pública que justifica o financiamento público ou sua autorização privada nos termos da lei.

Em síntese: a avaliação da educação superior é pré-condição para assegurar que a autonomia não isole as instituições autônomas dos controles do Estado e da sociedade, como se educação fosse um bem privatizável por entes públicos ou privados. Por outro lado, se internamente qualquer instituição de educação superior deve assegurar autonomia da comunidade em face dos seus mantenedores públicos ou privados, é pela democratização do acesso às instituições de ensino superior que se estabelece o elo entre elas e a sociedade que a mantém.

Se nem a avaliação, nem a autonomia são fins em si, apartados das sociedades, nacional ou regional, onde elas se inserem, ambas precisam assegurar a responsabilidade social das instituições de educação superior porque a educação é um bem público. Háuma nova conjuntura histórica da maior relevância que aumenta o desafio do governo e dos atores do processo de discussão da reforma universitária: as reformas de 1931 no governo Provisório de Vargas; e a de 1968 em plena ditadura militar, foram gestadas nas entranhas do poder em regimes autoritários.

Este é o grande desafio: pela primeira vez, desde 0 período anterior ao golpe militar, o tema da "reforma universitária" se desencadeia num contexto democrático, em meio a um debate aberto e participativo. Não se trata de criar uma "organização complexa" para realizar a sua modernização institucional. Este foi 0 projeto desenvolvido pela ditadura que modernizou a universidade. Este foi um avanço com relação à universidade tradicional, controlada pelas faculdades profissionais e seus catedráticos, mas este modelo, desde o início da Nova República, já dava sinais de esgotamento. ${ }^{23}$

Nesse início do século XXI, o Brasil precisa construir urgentemente uma instituição que seja a expressão de uma sociedade democrática e pluricultural, inspirada nos ideais de liberdade, de respeito pela diferença e de solidariedade, mas

${ }^{23}$ Basta citar o "Manifesto em D efesa da Universidade Pública", publicado em Belo Horizonte, em 1985, e a polêmica provocada com a ANDES e vários cientistas sociais: Sadi Dal Rosso; Simon Schwartzman; Octavio Velho e Fábio Wanderley Reis. In: Boletim Informativo e Bibliográfico em Ciências Sociais, (BIB), Rio de Janeiro, n. 19, 1ํㅗ sem / 1985, pp.21-65. 
que se constitua numa instância de consciência crítica em que a coletividade encontre seu espaço para repensar suas formas de vida e suas organizações sociais, econômica e políticas.

\section{Referenciasbibliográficas}

AVRITZER, Leonardo. A crise da universidade. Belo Horizonte, 2002 (mimeo).

AZEVED O, Fernando. A E ducação na encruzilhada. São Paulo: Melhoramentos, 1960.

BANCO MUND IAL. Construir Sociedades de Conocimiento: $\mathrm{N}$ uevos D esafios para la E ducación Terciaria, Washington, 2002.

BRASIL. Decreto no 19.851, de 11-04-1931. Brasília, SENADO FEDERAL. Subsecretaria de Informações.

BRASIL. R eforma U niversitária, G overno Costa e Silva. Relatório do G rupo de Trabalho, G ráfica do Colégio Pedro II, setembro 1968.

BRASIL. GERES - Grupo Executivo para reformulação da Educação Superior. Ante-projeto de lei e Relatório. In: E studos e D ebates, Brasília, n.13, 1987.

CARNOY, Martin. E stado e Teoria Política. Campinas, SP: Papirus, 1986. . Mondialisation et reforme de l'education Paris: UNESCO, 1999.

- E stá a educacão latino-americana preparando a força de trabalho para as economias do século X X I? Brasília: Unesco, 2004.

CUNHA, L. A. A U niversidade temporã: 0 ensino superior da Colônia a E ra V argas. Rio de Janeiro: Civilização Brasileira, 1980 . A universidade reformanda. Rio de Janeiro: Francisco Alves, 1988

. "Por uma lei orgânica da educação superior". In: Seminário U niversidade: por quê e para que reformar? MEC, Brasília, 2003.

D REIFUSS, R. 1964: a conquista do E stado. A cão política, poder e golpe de classe. Petrópolis, RJ: Vozes, 1981.

FÁVERO, Maria de Lourdes. A U D F. Rio de Janeiro: Ed. da UFRJ, 1989.

GENRO, Tarso. Aula Magna. Juiz de Fora (MG), março de 2004. (mimeo).

G UAD ILLA, Carmen G. "Balance de la década de los 90 y reflexiones sobre las nuevas fuerzas de cambio en la educación superior". In MOLLIS, Marcela (org.) L as universidades en A mérica L atina: reformadas 0 alteradas? L a cosmética del poder financiero. Buenos Aires: CLACSO, 2003. pp.9-17

- Situación y principales dinámicas de transformación de la educación superior en A mérica L atina, Caracas, CRESALC/ UNESCO, 1996

MATTEUCCI, Nicola (org). L 'U niversità nel mondo contemporâneo, Milano: Bompiani, 1991.

MOLLIS, Marcela (org.) L as universidades en A mérica Latina: reformadas 0 alteradas? L a cosmética del poder financiero. Buenos Aires: CLACSO, 2003.

ROD RIG UES, Roberto G. "La educación superior en el mercado: confuguraciones emergentes y nuevos proveedores". in MOLLIS, M. (org) L as universidades en A mérica L atina: reformadas 0 alteradas? L a cosmética del poder financiero. Buenos Aires: CLACSO, 2003. pp. 87-108.

SANTO S, Boaventura de Souza. "D a idéia de universidade à universidade de idéias". in Pelas mãos de A liœ. Porto: Afrontamento, 1994.

SEM AUTO R:

"Manifesto em D efesa da Universidade Pública". Boletim Informativo e Bibliográfico em Ciências Sociais (BIB). Rio de Janeiro, n. 19, 1ํㅗ sem / 1985. pp.21-65. 